\title{
Taiwan Drought was a Microcosm of Climate Change Adaptation Challenges in Complex Island Economies
}

\author{
Kathleen B. Aviso ${ }^{1} \cdot$ Chen-Fu Chien ${ }^{2} \cdot$ Ming K. Lim ${ }^{3} \cdot$ Raymond R. Tan ${ }^{1} \cdot$ Ming-Lang Tseng ${ }^{4}$ \\ Published online: 31 August 2021 \\ (c) The Author(s), under exclusive licence to Springer Nature Singapore Pte Ltd. 2021
}

Taiwan recently experienced a drought that illustrated the grim prospects for complex island economies in the face of climate change. The problem is distinct from threats to small island developing states (SIDS) with simpler resourcebased economies, whose vulnerability to climatic impacts is well-documented (Ourbak and Magnan 2018). Complex island economies are geographically confined microcosms of larger countries with highly diversified economies. Drought is expected to be one of the prevalent manifestations of climate change, potentially leading to a domino effect of socioeconomic impacts (Liu and Chen 2021). The California drought in the previous decade had adverse impacts on economic activities such as agriculture and electricity generation (Lund et al. 2018). Islands are more vulnerable to hydroclimatic impacts compared to contiguous regions in a large landmass, and those with complex economies are additionally prone to cascading losses through their industrial networks.

Water is a critical resource for many economic activities. Agriculture is clearly reliant on a reliable supply of water; prolonged drought can result in major economic losses and social unrest (Lund et al. 2018). Climate change adaptation strategies need to be developed for this sector to ensure food security (Iese et al. 2020). Since electricity generation is also water-dependent, drought can lead to reduced output from power plants (Lund et al. 2018; Byers et al. 2020).

Raymond R. Tan

raymond.tan@dlsu.edu.ph

1 Center for Engineering and Sustainable Development Research, De La Salle University, Manila, Philippines

2 Department of Industrial Engineering and Engineering Management, National Tsing Hua University, Hsinchu, Taiwan

3 Faculty Research Centre for Business in Society, Coventry University, Coventry, UK

4 Institute of Innovation and Circular Economy, Asia University, Taichung, Taiwan
Ensuing shortages of such basic commodities can lead to losses downstream in the supply chains. In addition to local impacts, indirect effects may also be felt outside the droughtaffected region. In export-oriented complex economies, water shortages can lead to economic ripple effects that propagate through global supply chains (Jung et al. 2009). For example, Taiwan's dominant position in the global semiconductor foundry means that drought-induced supply chain bottlenecks can manifest in the shortage of consumer electronic products.

The recent water crisis in Taiwan underscores the need for climate proofing of complex island economies (Tan et al. 2017). Poorly designed water policies can lead to a tragedy of the commons, so better measures to deal with future hydroclimatic crises need to be developed. For example, industrial water conservation is an important climate change adaptation strategy (Tan and Foo 2018). Large-scale water recycling has already been demonstrated as a workable solution in Singapore, another complex island economy. Other adaptation strategies such as precision irrigation or switching to low-water footprint crops will also be needed in agriculture (Jung et al. 2009). During a crisis, the optimal allocation of water resources across economic sectors and geographic regions can mitigate the impact of droughts (Ye et al. 2018). Finally, just as space exploration provides circular economy insights via the "Spaceship Earth" analogy (Paladini et al. 2021), complex island economies also provide microcosms that can be valuable proving ground for sustainable technologies to be deployed on a global scale in the future.

\section{References}

Byers EA, Coxon G, Freer J, Hall JW (2020) Drought and climate change impacts on cooling water shortages and electricity prices in Great Britain. Nat Commun 11:2239 
Iese V, Halavatau S, N'Yeurt ADR, Wairiu M, Holland E, Dean A, Veisa F, Patolo S, Havea R, Bosenaqali S, Navunicagi O (2020) Agriculture under a changing climate. In: Kumar L (ed) Climate change and impacts in the Pacific. Cham, Springer Nature, pp 323-357

Jung J, Santos JR, Haimes YY (2009) International Trade Inoperability Input-Output Model (IT-IIM): Theory and application. Risk Anal 29:137-154

Liu Y, Chen J (2021) Future global socioeconomic risk to droughts based on estimates of hazard, exposure, and vulnerability in a changing climate. Sci Total Environ 751:142159

Lund J, Medellin-Azuara J, Durand J, Stone K (2018) Lessons from California's 2012-2016 Drought. J Water Resour Plan Manag 144:04018067

Ourbak T, Magnan AK (2018) The Paris agreement and climate change negotiations: Small Islands, big players. Reg Environ Change 18:2201-2207

Paladini S, Saha K, Pierron X (2021) Sustainable space for a sustainable Earth? Circular economy insights from the space sector. J Environ Manag 289:112511
Tan RR, Foo DCY (2018) Integrated multi-scale water management as a climate change adaptation strategy. Clean Technol Environ Policy 20:1123-1125

Tan RR, Aviso KB, Chiu ASF, Promentilla MAB, Razon LF, Tseng M-L, Yu KDS (2017) Towards "climate-proof" industrial networks. Resour Conserv Recycl 127:244-245

Ye Q, Li Y, Zhuo L, Zhang W, Xiong W, Wang C, Wang P (2018) Optimal allocation of physical water resources integrated with virtual water trade in water scarce regions: A case study for Beijing, China. Water Res 129:264-276

Publisher's Note Springer Nature remains neutral with regard to jurisdictional claims in published maps and institutional affiliations. 